\title{
Blood Flow during Cardiopulmonary Resuscitation with Simultaneous Compression and Ventilation in Infant Pigs
}

\author{
IVOR D. BERKOWITZ, TEERACHAI CHANTAROJANASIRI, RAYMOND C. KOEHLER, \\ CHARLES L. SCHLEIEN, J. MICHAEL DEAN, JOHN R. MICHAEL, MARK C. ROGERS, AND \\ RICHARD J. TRAYSTMAN
}

The Department of Anesthesiology/Critical Care Medicine, The Johns Hopkins Medical Institution, Baltimore, Maryland 21205

\begin{abstract}
We determined whether the simultaneous chest compression and ventilation (SCV) technique of cardiopulmonary resuscitation (CPR) enhances cerebral (CBF) and myocardial (MBF) blood flows and cerebral $\mathrm{O}_{2}$ uptake in an infant swine model of CPR as it does in most adult animal CPR models. We also tested whether SCVCPR sustains CBF and MBF for prolonged periods of CPR when these flows ordinarily deteriorate. CPR was performed in two groups $(n=8)$ of pentobarbital anesthetized piglets $(3.5-5.5 \mathrm{~kg}$ ) with continuous epinephrine infusion $(10 \mu \mathrm{g} / \mathrm{kg} / \mathrm{min})$. Conventional CPR was performed at 100 compressions/min, $60 \%$ duty cycle, $1: 5$ breath to compression ratio and $25-30 \mathrm{~mm} \mathrm{Hg}$ peak airway pressure. SCVCPR was performed at 60 compressions $/ \mathrm{min}, 60 \%$ duty cycle and $60 \mathrm{~mm} \mathrm{Hg}$ peak airway pressure applied during each chest compression. Peak right atrial and aortic pressures in excess of $80 \mathrm{~mm} \mathrm{Hg}$ were generated during CPR in both groups. At $5 \mathrm{~min}$ of conventional and SCV-CPR, MBF was $38 \pm 7$ and $46 \pm 7 \mathrm{~mL} \cdot \mathrm{min}^{-1} \cdot 100 \mathrm{~g}^{-1}( \pm \mathrm{SE})$, respectively, and $\mathrm{CBF}$ was $15 \pm 3$ and $13 \pm 2 \mathrm{~mL} \cdot \mathrm{min}^{1}$. $100 \mathrm{~g}^{-1}$, respectively. However, as CPR was prolonged to $50 \mathrm{~min}$, the sternum progressively lost its recoil and the chest became more deformed. Lung inflation at high airway pressure with SCV-CPR did not prevent this chest deformation. Aortic pressure gradually declined, whereas right atrial and intracranial pressure remained constant in both groups. Consequently, MBF and CBF fell less than 10 $\mathrm{mL} \cdot \mathrm{min}^{-1} \cdot 100 \mathrm{~g}^{-1}$ and cerebral $\mathrm{O}_{2}$ uptake was markedly impaired during prolonged conventional and SCV-CPR. Therefore, SCV-CPR in an infant swine model does not enhance MBF and CBF during early CPR because intrathoracic pressure generation is already high with conventional CPR as reflected by the high right atrial pressure. In addition, SCV-CPR does not prevent the progressive chest deformation and the subsequent decline in $\mathrm{CBF}$ and MBF when CPR is prolonged, as is often required in pediatric resuscitation. (Pediatr Res 26: 558-564, 1989)
\end{abstract}

\section{Abbreviations}

CPR, cardiopulmonary resuscitation

SCV-CPR, simultaneous compression and ventilation cardiopulmonary resuscitation

Received October 5, 1988; accepted July 27, 1989.

Correspondence and reprint requests to Ivor D. Berkowitz, M.D., Department of Anesthesiology/Critical Care Medicine, The Johns Hopkins Hospital, 600 North Wolfe Street-Halsted 842, Baltimore, MD 21205.

Supported by USPHS NIH Grant NS20020.
CBF, cerebral blood flow

MBF, myocardial blood flow

The hypothesis that antegrade blood flow during closed ches CPR is due not to direct cardiac compression but to phas increases in intrathoracic pressure $(1,2)$ has led to the invest gation of alternative techniques of CPR in adult animals (3-5 According to this thoracic pump mechanism, external che compression produces a generalized elevation of intrathoraci pressure that is transmitted to all thoracic vascular structure Pressure in intrathoracic arteries is transmitted to extrathorac arteries, but jugular venous valves and possibly collapse of vei at the thoracic inlet prevent full transmission of intrathora pressure to the extrathoracic veins. Consequently, uneven trans mission of intrathoracic pressure to the extrathoracic arterial and venous system provides a gradient for antegrade blood flo during chest compression $(1,2)$.

In large adult dogs, conventional CPR using sternal compres. sion generates low intrathoracic and vascular pressures, an correspondingly low $\mathrm{CBF}$ and MBF. However, changing to SCV. CPR generates higher intrathroacic and vascular pressures (3) and enhances cerebral and myocardial perfusion $(4,6)$, particu larly when epinephrine is continuously infused (7). In man, SCV. CPR also increases blood pressure and carotid artery blood flow (8).

Less experimental data are available in pediatric anima models of CPR (9). In 6- to 12-wk-old dogs, cerebral blood flow levels with conventional CPR are reported to be as low as in adult dogs (10). In 2-wk-old pigs, in contrast, conventional CPR is effective in generating high levels of cerebral and myocardia blood flow, especially when epinephrine is infused (11). Age related and possibly species differences in chest deformability and geometry permit the generation of higher intrathoracic pr sure and myocardial and cerebral perfusion in immature pig (12). These high blood flows, however, deteriorate after $35 \mathrm{~min}$ of CPR to levels lower than were achieved with prolonged CPR in adult dogs (11). The mechanisms of this decline are poorl understood. With prolonged CPR the compliant chest wall of the infant pig loses its recoil and progressive chest deformation develops $(11,12)$. This may distort intrathoracic veins an impede venous return. We postulated that lung inflation ventilation at high airway pressure during SCV-CPR may preve the progressive chest deformation and mitigate its interferen with venous return. In addition, cyclic lung inflation itself assist in propelling blood under certain conditions (13, 14).

The purpose of our study was to determine whether SCV-CP. 
further enhance cerebral and myocardial blood flow and $\mathrm{ral} \mathrm{O}_{2}$ uptake in an infant swine model of CPR, particularly prolonged CPR when the conventional technique fails. use resuscitation after cardiac arrest in children is frequently racted (15), it is critical to be able to maintain an adequate organ perfusion until spontaneous circulation can be rered.

\section{MATERIALS AND METHODS}

Animal preparation. The protocol for these studies has been proved by the Animal Care and Use Committee of the Johns popkins Medical Institutions. All experiments were performed 3.5 to $5.5 \mathrm{~kg}, 2$-wk-old infant swine. The animals were esthetized initially with pentobarbital $(30-40 \mathrm{mg} / \mathrm{kg}$ intraperneally). Supplemental pentobarbital was administered intranously as needed during surgery. Animals were ventilated via tracheostomy by a Harvard animal ventilator (Harvard Appaus, Co. Inc., Millis, MA), with an inspired $\mathrm{O}_{2}$ of approximately . End tidal $\mathrm{CO}_{2}$ was monitored during the prearrest period o maintain arterial $\mathrm{CO}_{2}$ tension $\left(\mathrm{PaCO}_{2}\right)$ at $35-45 \mathrm{~mm} \mathrm{Hg}$. aline-filled catheters were placed into the right atrium, thoracic orta, and left ventricle via femoral vessel cannulation. Catheters ere also placed into the axillary veins for fluid and drug admintration and into the proximal subclavian artery via axillary rerial cannulation. A burr hole was made in the skull over the nidline and a catheter was placed in the sagittal sinus with the p positioned $1-2 \mathrm{~cm}$ anterior to the confluence of the sinus. A raight ventricular catheter (Cordis, Miami, FL) was placed hrough another burr hole into the lateral ventricle for intracraial pressure measurement. A bipolar electrode was placed via a moral vein into the right heart to induce ventricular fibrillation. ifter the surgery was completed, pancuronium $(0.2 \mathrm{mg} / \mathrm{kg})$ was iministered. Heparin (1000 U) was given before cardiac arrest ras induced.

Measurements. Pressures were measured from the intrathoacic aorta, right atrium, sagittal sinus, and lateral ventricle with Slatham P23Db transducers (Statham Instruments, Inc., Hato Rey, PR) referenced to the level of the right atrium. Arterial and gittal sinus blood gases were measured on a Radiometer BMS3 tectrode and analyzer system (Radiometer, Copenhagen, Dennark). Oxygen content was measured by $\mathrm{Lex}_{-} \mathrm{O}_{2}$-Con fuel cell stem (Lexington Instruments, Waltham, MA). Hb concentraon was measured with a CO-Oximeter (model 282, Instrumention Laboratory, Inc., Lexington, MA).

Regional blood flow was measured with microspheres labeled ith ${ }^{153} \mathrm{Gd},{ }^{51} \mathrm{Cr},{ }^{113} \mathrm{Sn},{ }^{103} \mathrm{Ru},{ }^{95} \mathrm{Nb}$, and ${ }^{46} \mathrm{Sc}$ (Dupont-New gland Nuclear Products, Boston, MA). Use of the microsphere whnique during CPR has been previously validated $(4,11)$. Ipproximately $1 \times 10^{6}$ microspheres $(16 \pm 0.5 \mu \mathrm{m}$ diameter $)$ cre injected into the left ventricle for each prearrest measureent and $5 \times 10^{5}$ microspheres were injected for each of the ostarrest measurements. Reference blood samples were withlawn from the subclavian artery for 2 min after the control jection and for $4.5 \mathrm{~min}$ after each postarrest microsphere jection. The reference sample withdrawal rate was $3.8 \mathrm{~mL} /$ in for the prearrest measurement and $1.9 \mathrm{~mL} / \mathrm{min}$ for each jection during CPR. This combination of injection doses and thdrawal rates ensured that there were at least 2000 microtheres in the reference sample before cardiac arrest was induced and at least 10000 microspheres during CPR. Vials of blood id tissue were counted on a multichannel autogamma scintiltion spectrometer (model 9042, Packard Instrument Co., owners Grove, IL). Tissue blood flow was calculated by the andard simultaneous equation technique (16). It was assumed at the contamination of sagittal sinus blood from sources other an the brain, such as dura and skull bone is small, particularly ring CPR when blood flow to these extracranial tissues is duced (4)
At the end of each experiment, postmortem examination was performed to confirm catheter positions and to exclude the presence of a pneumothorax. The entire heart and brain were removed and tissue samples of kidney, jejunum, facial skin, facial muscle, and tongue were obtained. The heart was cut into sections of left ventricular free wall, interventricular septum, and right ventricular free wall. The brain was dissected into medulla, pons, midbrain, cerebellum and diencephalon, and cerebrum. Cerebral $\mathrm{O}_{2}$ uptake was calculated from the arterial-sagittal sinus $\mathrm{O}_{2}$ content difference and blood flow to the cerebrum. Cerebral fractional $\mathrm{O}_{2}$ extraction equals the arterial-sagittal sinus $\mathrm{O}_{2}$ content difference divided by the arterial $\mathrm{O}_{2}$ content.

Experimental protocol. At least $90 \mathrm{~min}$ before CPR, $50 \mathrm{~mL}$ of blood was withdrawn from each animal and replaced with 200 $\mathrm{mL}$ of Ringer's lactate solution. This blood, diluted 1:1 with Ringer's lactate solution, was then infused at $3.4 \mathrm{~mL} / \mathrm{min}$ when the reference samples were withdrawn during CPR to replace the blood volume. The animal was placed supine and secured to a $\mathrm{V}$-shaped board that was attached to the baseplate of the mechanical chest compressor. Ventricular fibrillation was induced by passing a $60 \mathrm{~Hz}$ alternating current through the bipolar electrode in the right heart. External chest compression was begun about $15 \mathrm{~s}$ later with a pneumatic chest compressor (Thumper, Michigan Instruments, Grand Rapids, MI) equipped with a pediatric chest pad. This pad $(8.0 \times 5.5 \mathrm{~cm})$ has a solid rubber hemisphere ( $3 \mathrm{~cm}$ diameter) molded in its center to apply the force over a smaller surface area than the adult pad. The pad was centered over the lower half of the sternum, 3-4 cm cephalad to the xiphoid. A pressure-limited ventilator was used during CPR. The pneumatic chest compressor and ventilator were synchronized by a microprocessor controller.

Animals were randomly assigned to conventional CPR or SCV-CPR groups. In the conventional CPR group $(n=8)$, CPR was performed at a compression rate of $100 / \mathrm{min}$ with a $60 \%$ duty cycle. Ventilation with $100 \%$ oxygen and peak airway pressures of $25-30 \mathrm{~mm} \mathrm{Hg}$ was interposed after every fifth chest compression. In the SCV-CPR group $(n=8)$, chest compression was performed at 60 compressions/min with a $60 \%$ duty cycle. Ventilation was simultaneous with chest compression and peak airway pressures was set at $60 \mathrm{~mm} \mathrm{Hg}$. A ventilating gas mixture of $95 \% \mathrm{O}_{2}-5 \% \mathrm{CO}_{2}$ was used in an attempt to maintain $\mathrm{PaCO}_{2}$ at comparable levels with the conventional CPR group. Applied chest force prevented overdistention of the lung at high airway pressures during SCV-CPR. In preliminary experiments, SCVCPR performed at rates more than $60 / \mathrm{min}$ or at peak airway pressures greater than $60 \mathrm{~mm} \mathrm{Hg}$ often caused pneumothoraces. In both CPR groups, the force of the Thumper was adjusted initially to produce a $20 \%$ displacement of the animals' baseline anteroposterior chest diameter, measured at the lower half of the sternum. Once this displacement had been achieved, no further force adjustments were made during the $55 \mathrm{~min}$ of continuous CPR. Force was measured by a strain gauge on the Thumper and piston displacement was measured by a sliding potentiometer built into the Thumper.

To better maintain perfusion pressures during CPR, each animal received a $40 \mu \mathrm{g} / \mathrm{kg}$ bolus of epinephrine through the left ventricular catheter at the onset of CPR, followed by a continuous right atrial infusion of $10 \mu \mathrm{g} / \mathrm{kg} / \mathrm{min}$ epinephrine in saline. The rate of this infusion was $3.4 \mathrm{~mL} / \mathrm{min}$. Blood flow, pressure, and blood gas measurements were made pre-arrest and at 5, 10, 20,35 , and $50 \mathrm{~min}$ of CPR.

Statistical analysis. Data were analyzed with two-way analysis of variance with repeated measures over time during CPR. Mean values were compared by the Duncan new multiple-range test. Prearrest values were not included in the analysis because the variance of most measurements differed considerably from the variance during CPR. Prearrest values were compared between groups with the unpaired test. Statistical significance was set at $p$ $<0.05$. Values are presented as mean \pm SEM. 


\section{RESULTS}

Original records obtained during conventional CPR with intermittent ventilation and during SCV-CPR with high airway pressure are shown in Figure 1. Sternal displacement (the difference between the position of the Thumper piston at endcompression or "systole" and end relaxation or "diastole") was set at $20 \%$ of the initial anteroposterior chest diameter and remained unchanged for the duration of CPR. The chest did not completely recoil during the relaxation phase. The difference between the end-expiratory position of the Thumper pad resting on the sternum before arrest and the position at end-relaxation during CPR is defined as chest deformity. This increased progressively over the course of CPR with both types of CPR. Right atrial systolic pressure, a reflection of intrathoracic pressure, remained unchanged for the duration of CPR with both CPR modalities. The aortic systolic pressure, in contrast, progressively declined over time. Sagittal sinus pressure and intracranial pressure increased phasically with each chest compression, but to a lesser extent than the right atrial systolic pressure.

In the conventional CPR and SCV-CPR groups, cyclic sternal displacement was $19.4 \pm 0.4$ and $21 \pm 0.8 \%$ of the baseline anteroposterior chest diameter, respectively. The corresponding was $14 \pm 2$ and $13 \pm 2 \%$ of baseline anteroposterior diameter at $5 \mathrm{~min}$ of CPR in the respective groups, and it increased $21 \pm 2$ and $20 \pm 3 \%$, respectively, at $50 \mathrm{~min}$ of CPR. There was no difference in sternal displacement, chest deformity or compression force at any time point between groups. Before arrest, chest shape as measured by the ratio of the anteroposterior to lateral chest diameter was similar in the conventional CPR $(0.95 \pm$ $0.03)$ and SCV-CPR $(0.92 \pm 0.02)$ groups.

Peak right atrial pressure was $83 \pm 10$ and $101 \pm 6 \mathrm{~mm} \mathrm{Hg}$ at $5 \mathrm{~min}$ and $81 \pm 8$ and $96 \pm 10 \mathrm{~mm} \mathrm{Hg}$ at $50 \mathrm{~min}$ in the conventional CPR and SCV-CPR groups, respectively. There was no augmentation at any time in peak right atrial pressure in the SCV-CPR group compared with the conventional CPR group and this pressure remained unchanged for the duration of CPR in both groups (Fig. 2). Peak aortic pressure, however, gradually compression force was $241 \pm 20$ and $232 \pm 22 \mathrm{~N}$. Chest deformity declined to the same extent in each group with prolonged $\mathrm{CPR}$ declined to $64 \pm 6$ and $81 \pm 8$ at $50 \mathrm{~min}$ in the respective groups There was no difference between the two groups. Aortic pressur during the relaxation phase declined progressively during the and from $32 \pm 2$ to $14 \pm 3 \mathrm{~mm} \mathrm{Hg}$ with SCV-CPR. Right atrial the pressure gradient for coronary flow declined during the course of CPR in both groups (shaded area in Fig. 2).

Substantial levels of total myocardial blood flow were obtained over the first $10 \mathrm{~min}$ of CPR, but flow declined when CPR was right ventricle and septum all responded similarly (Table I). myocardial blood flow between the CPR groups.

Total brain blood flow decreased progressively over the dura.

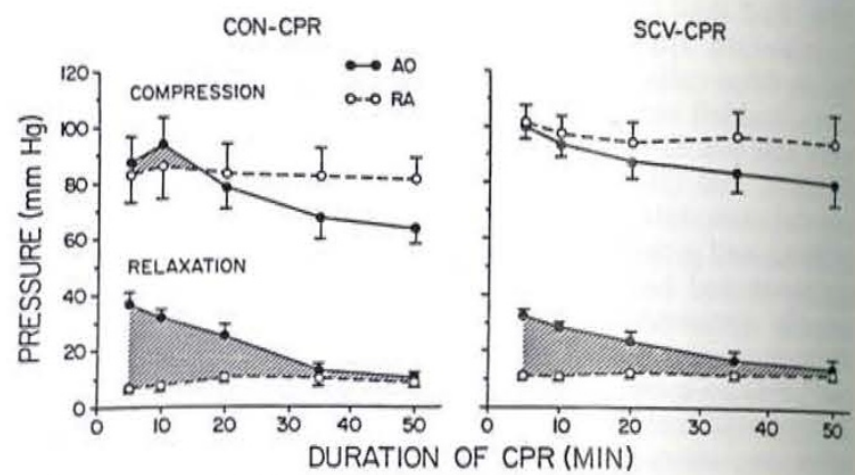

Fig. 2. Aortic $(A O)$ and right atrial $(R A)$ systolic (compression phase) and diastolic (relaxation phase) pressures during $50 \mathrm{~min}$ of conventional $(C O N)(l e f t)$ and simultaneous compression and ventilation (SCV) CPR (right). Shaded areas reflect magnitude of positive aortic-right atrial pressure gradients for antegrade MBF. (Fig. 2). At $5 \mathrm{~min}$ the aortic systolic pressure was $88 \pm 9$ and 10 $\pm 5 \mathrm{~mm} \mathrm{Hg}$ in the conventional and SCV-CPR groups bu course of CPR from $37 \pm 4$ to $10 \pm 2$ with conventional the pressure during the relaxation phase remained unchanged. Thus, prolonged in both groups (Fig. 3). Blood flow to the left ventricle, There were no differences at any time point in total or regional

ion of CPR and There was no di the cerebellui CPR, however, $\mathrm{f}$ roup than in infratentorial rę torial regions in

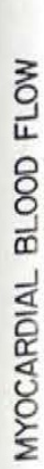

60 .

¿$$
50 \text {. }
$$

Fig. 3. MBF dur compression and ve

\section{$\mathrm{T:}$}

Brain

Cerebrum

Cerebellun

Medulla

Pons

Midbrain

Diencephal

Heart

Left ventric

Right ventr

Septum

Cephalic tissu Tongue

Facial skin

Facial musc

Visceral organ Kidney

Jejunum

I. Representative experimental tracings of airway pressure $(A W P)$, aortic pressure $(A O P)$, right atrial pressure $(R A P)$, intracranial pressurc $(I C P)$, and piston position at 5 and $50 \mathrm{~min}$ of conventional and simultaneous compression and ventilation $(S C V)$ CPR. Chest deformity is the difference between the position of the Thumper pad resting on the sternum before arrest $(0 \mathrm{~cm})$ and the position at end relaxation. AOP declined with prolonged CPR with both CPR modes, yet RAP, ICP and sternal displacement remained unchanged. Progressive chest deformity developed in both CPR groups with prolonged CPR. 
th prolonged $\mathrm{CPR}$ 'as $88 \pm 9$ and 10 -CPR groups bu respective groups ps. Aortic pressure ssively during the onventional CPR -CPR. Right atrial unchanged. Thus 1 during the course low were obtained zd when CPR was 0 the left ventricle nilarly (Table 1) n total or regional ps.

ely over the dura-

SCV-CPR
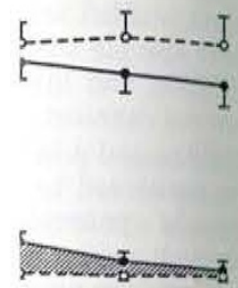

$\begin{array}{llll}0 & 30 & 40 & 50\end{array}$

(compression phase) min of conventional tilation (SCV) CPR re aortic-right atrial

ntracranial pressure est deformity is the Ition. AOP declined ormity developed in ion of CPR and to the same extent in both CPR groups (Fig. 4). there was no difference between groups in regional blood flow the cerebellum, pons, midbrain, or cerebrum. At $10 \mathrm{~min}$ of CPR, however, flow to the medulla was greater in the SCV-CPR roup than in the conventional CPR group. Blood flow to foutentorial regions declined to a lesser extent than supratenorial regions in both groups during CPR (Table 1).

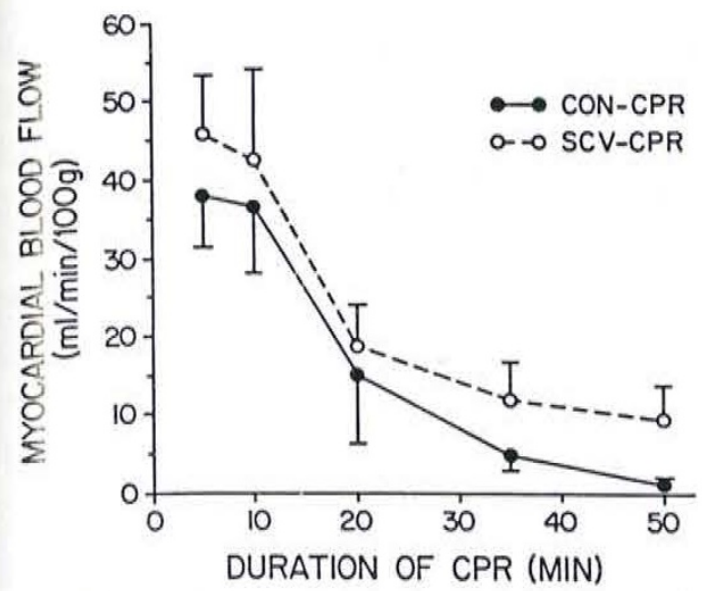

Fig. 3. $\mathrm{MBF}$ during $50 \mathrm{~min}$ of conventional $(\mathrm{CON})$ and simultaneous compression and ventilation (SCV) CPR.
There were no differences between the CPR groups in arterial $\mathrm{PO}_{2}, \mathrm{pH}, \mathrm{Hb}$ concentration, and oxygen saturation during CPR (Table 2). Arterial $\mathrm{PCO}_{2}$, however, was higher in the SCV-CPR group. In both groups, cerebral fractional $\mathrm{O}_{2}$ extraction increased to near-maximum levels throughout $\mathrm{CPR}$, but cerebral $\mathrm{O}_{2}$ uptake fell progressively during CPR (Table 2). Cerebral $\mathrm{O}_{2}$ uptake was not different between groups, except at $5 \mathrm{~min}$ when the value in the conventional CPR group was higher than in the SCV-CPR group. Mean intracranial pressure and mean sagittal sinus pres-

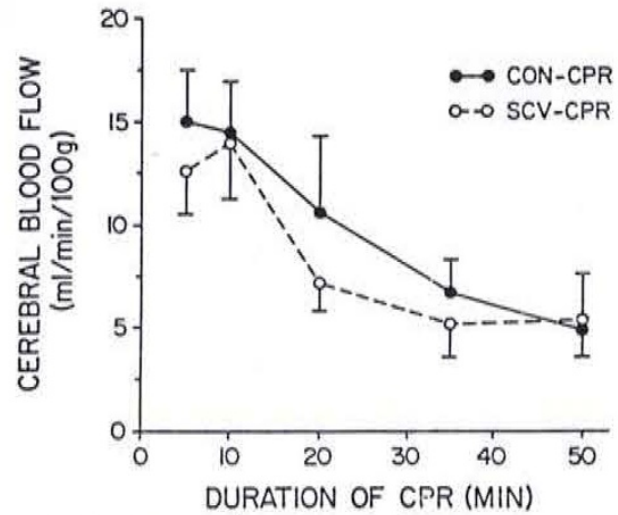

Fig. 4. CBF during $50 \mathrm{~min}$ of conventional $(C O N)$ and simultaneous compression and ventilation $(S C V) C P R$.

Table 1. Regional blood flow $\left(\mathrm{mL} \cdot \mathrm{min}^{-1} \cdot 100 \mathrm{~g}^{-1}\right)$ before cardiac arrest and during prolonged $C P R^{*}$

\begin{tabular}{|c|c|c|c|c|c|c|c|}
\hline & Group & Before arrest & $5 \mathrm{~min}$ & $10 \mathrm{~min}$ & $20 \mathrm{~min}$ & $35 \mathrm{~min}$ & $50 \mathrm{~min}$ \\
\hline \multicolumn{8}{|l|}{ Brain } \\
\hline \multirow[t]{2}{*}{ Cerebrum } & I & $50 \pm 8$ & $13 \pm 3$ & $11 \pm 2$ & $8 \pm 3$ & $4 \pm 2$ & $2 \pm 1$ \\
\hline & II & $53 \pm 5$ & $9 \pm 2$ & $9 \pm 2$ & $4 \pm 1$ & $2 \pm 1$ & $3 \pm 1$ \\
\hline \multirow[t]{2}{*}{ Cerebellum } & $\mathrm{I}$ & $65 \pm 8$ & $22 \pm 2$ & $24 \pm 4$ & $17 \pm 5$ & $12 \pm 3$ & $8 \pm 2$ \\
\hline & II & $72 \pm 7$ & $23 \pm 4$ & $27 \pm 6$ & $15 \pm 3$ & $10 \pm 3$ & $10 \pm 4$ \\
\hline \multirow[t]{2}{*}{ Medulla } & I & $56 \pm 7$ & $22 \pm 2$ & $25 \pm 2$ & $26 \pm 5$ & $26 \pm 3$ & $21 \pm 4$ \\
\hline & II & $71 \pm 13$ & $38 \pm 6$ & $48 \pm 12 \dagger$ & $31 \pm 11$ & $24 \pm 8$ & $23 \pm 8$ \\
\hline \multirow[t]{2}{*}{ Pons } & I & $57 \pm 11$ & $20 \pm 2$ & $21 \pm 3$ & $18 \pm 3$ & $18 \pm 3$ & $14 \pm 3$ \\
\hline & II & $54 \pm 9$ & $24 \pm 5$ & $31 \pm 7$ & $22 \pm 5$ & $18 \pm 6$ & $17 \pm 6$ \\
\hline \multirow[t]{2}{*}{ Midbrain } & I & $62 \pm 11$ & $22 \pm 2$ & $22 \pm 3$ & $16 \pm 4$ & $14 \pm 4$ & $10 \pm 3$ \\
\hline & II & $64 \pm 9$ & $18 \pm 3$ & $20 \pm 3$ & $12 \pm 3$ & $11 \pm 4$ & $12 \pm 5$ \\
\hline \multirow[t]{2}{*}{ Diencephalon } & I & $46 \pm 8$ & $16 \pm 2$ & $16 \pm 2$ & $11 \pm 4$ & $9 \pm 2$ & $6 \pm 1$ \\
\hline & II & $47 \pm 5$ & $12 \pm 2$ & $13 \pm 2$ & $8 \pm 2$ & $7 \pm 2$ & $8 \pm 3$ \\
\hline \multicolumn{8}{|l|}{ Heart } \\
\hline \multirow[t]{2}{*}{ Left ventricle } & I & $224 \pm 43$ & $44 \pm 8$ & $44 \pm 11$ & $15 \pm 7$ & $5 \pm 2$ & $2 \pm 1$ \\
\hline & II & $271 \pm 56$ & $51 \pm 9$ & $46 \pm 13$ & $20 \pm 7$ & $13 \pm 6$ & $8 \pm 5$ \\
\hline \multirow[t]{2}{*}{ Right ventricle } & I & $220 \pm 43$ & $44 \pm 7$ & $40 \pm 7$ & $16 \pm 8$ & $5 \pm 2$ & $2 \pm 1$ \\
\hline & II & $233 \pm 37$ & $55 \pm 9$ & $54 \pm 15$ & $25 \pm 8$ & $14 \pm 6$ & $13 \pm 6$ \\
\hline \multirow[t]{2}{*}{ Septum } & I & $277 \pm 76$ & $35 \pm 7$ & $33 \pm 9$ & $13 \pm 9$ & $4 \pm 2$ & $1 \pm 1$ \\
\hline & II & $247 \pm 44$ & $43 \pm 7$ & $38 \pm 11$ & $16 \pm 7$ & $11 \pm 5$ & $8 \pm 4$ \\
\hline \multicolumn{8}{|l|}{ Cephalic tissues } \\
\hline \multirow[t]{2}{*}{ Tongue } & I & $6 \pm 1$ & $0.5 \pm 0.1$ & $0.5 \pm 0.2$ & $0.7 \pm 0.2$ & $0.9 \pm 0.2$ & $1.1 \pm 0.2$ \\
\hline & II & $7 \pm 1$ & $0.3 \pm 0.1$ & $0.4 \pm 0.1$ & $0.5 \pm 0.2$ & $0.9 \pm 0.2$ & $0.8 \pm 0.4$ \\
\hline \multirow[t]{2}{*}{ Facial skin } & I & $3 \pm 1$ & 0 & 0 & 0 & 0 & 0 \\
\hline & II & $3 \pm 1$ & 0 & 0 & 0 & 0 & 0 \\
\hline \multirow[t]{2}{*}{ Facial muscle } & I & $5 \pm 1$ & $0.1 \pm 0.1$ & $0.1 \pm 0.1$ & $0.2 \pm 0.1$ & $0.2 \pm 0.1$ & $0.3 \pm 0.1$ \\
\hline & II & $5 \pm 1$ & $0.1 \pm 0.1$ & $0.1 \pm 0.1$ & $0.1 \pm 0.1$ & $0.1 \pm 0.1$ & $0.2 \pm 0.1$ \\
\hline \multicolumn{8}{|l|}{ Visceral organs } \\
\hline \multirow[t]{2}{*}{ Kidney } & I & $140 \pm 17$ & $0.1 \pm 0.1$ & 0 & $0.1 \pm 0.1$ & 0 & 0 \\
\hline & II & $135 \pm 18$ & 0 & 0 & 0 & 0 & 0 \\
\hline \multirow[t]{2}{*}{ Jejunum } & I & $37 \pm 8$ & $2.4 \pm 0.7$ & $3.3 \pm 0.7$ & $3.7 \pm 1.4$ & $1.6 \pm 0.7$ & $0.9 \pm 0.4$ \\
\hline & II & $35 \pm 5$ & $1.3 \pm 0.6$ & $4.1 \pm 2$ & $3.0 \pm 1$ & $1.3 \pm 0.5$ & $0.5 \pm 0.2$ \\
\hline
\end{tabular}

'Group I, conventional CPR; group II, SCV-CPR.

$4 p<0.05$ versus group I value. 
Table 2. Blood analyses, cerebral $\mathrm{O}_{2}$ uptake, intracranial, and sagittal sinus pressures*

\begin{tabular}{|c|c|c|c|c|c|c|c|}
\hline & Group & Before arrest & $5 \mathrm{~min}$ & $10 \mathrm{~min}$ & $20 \mathrm{~min}$ & $35 \mathrm{~min}$ & $50 \mathrm{~min}$ \\
\hline Arterial $\mathrm{PO}_{2}(\mathrm{~mm} \mathrm{Hg})$ & $\begin{array}{l}\text { I } \\
\text { II }\end{array}$ & $\begin{array}{l}133 \pm 11 \\
101 \pm 5\end{array}$ & $\begin{array}{l}207 \pm 30 \\
283 \pm 24\end{array}$ & $\begin{array}{l}171 \pm 33 \\
202 \pm 32\end{array}$ & $\begin{array}{l}142 \pm 32 \\
191 \pm 39\end{array}$ & $\begin{array}{l}120 \pm 24 \\
176 \pm 40\end{array}$ & $\begin{array}{r}88 \pm 16 \\
163 \pm 46\end{array}$ \\
\hline $\begin{array}{l}\text { Arterial } \mathrm{PCO}_{2}(\mathrm{~mm} \mathrm{Hg}) \\
\text { Arterial } \mathrm{pH}\end{array}$ & $\begin{array}{r}\text { I } \\
\text { II } \\
\text { I } \\
\text { II }\end{array}$ & $\begin{array}{c}39 \pm 1 \\
39 \pm 1 \\
7.38 \pm 0.01 \\
7.39 \pm 0.01\end{array}$ & $\begin{aligned} 20 & \pm 3 \\
38 & \pm 6 \dagger \\
7.53 & \pm 0.05 \\
7.38 & \pm 0.01\end{aligned}$ & $\begin{aligned} 27 & \pm 3 \\
44 & \pm 7 \\
7.29 & \pm 0.05 \\
7.17 & \pm 0.09\end{aligned}$ & $\begin{aligned} 32 & \pm 6 \\
59 & \pm 7 \dagger \\
7.08 & \pm 0.05 \\
6.92 & \pm 0.05\end{aligned}$ & $\begin{aligned} 40 & \pm 7 \\
72 & \pm 9 \uparrow \\
6.91 & \pm 0.05 \\
6.77 & \pm 0.04\end{aligned}$ & $\begin{aligned} 52 & \pm 9 \\
89 & \pm 10 \dagger \\
6.73 & \pm 0.05 \\
6.62 & \pm 0.04\end{aligned}$ \\
\hline Arterial $\mathrm{Hb}(\mathrm{g} / \mathrm{dL})$ & $\begin{array}{l}\text { I } \\
\text { II }\end{array}$ & $\begin{array}{r}10.2 \pm 0.7 \\
8.3 \pm 0.8\end{array}$ & $\begin{array}{l}9.7 \pm 0.6 \\
8.6 \pm 1.1\end{array}$ & $\begin{array}{l}8.4 \pm 0.4 \\
7.5 \pm 1.1\end{array}$ & $\begin{array}{l}7.3 \pm 0.5 \\
6.3 \pm 0.9\end{array}$ & $\begin{array}{l}6.2 \pm 0.6 \\
5.3 \pm 0.8\end{array}$ & $\begin{array}{l}4.5 \pm 0.4 \\
4.1 \pm 0.6\end{array}$ \\
\hline Arterial $\mathrm{O}_{2}$ saturation (\%) & $\begin{array}{l}\text { I } \\
\text { II }\end{array}$ & $\begin{aligned} 100 & \pm 1 \\
98 & \pm 1\end{aligned}$ & $\begin{array}{r}96 \pm 4 \\
100 \pm 1\end{array}$ & $\begin{array}{l}97 \pm 3 \\
95 \pm 5\end{array}$ & $\begin{array}{l}93 \pm 3 \\
91 \pm 6\end{array}$ & $\begin{array}{l}85 \pm 7 \\
87 \pm 7\end{array}$ & $\begin{array}{l}76 \pm 9 \\
78 \pm 1\end{array}$ \\
\hline Arterial $\mathrm{O}_{2}$ content $(\mathrm{mL} / \mathrm{dL})$ & $\begin{array}{l}\text { I } \\
\text { II }\end{array}$ & $\begin{array}{l}13.9 \pm 0.8 \\
11.1 \pm 1.0\end{array}$ & $\begin{array}{r}14 \pm 1.2 \\
12.3 \pm 1.5\end{array}$ & $\begin{array}{l}11.9 \pm 0.8 \\
10.4 \pm 1.6\end{array}$ & $\begin{array}{l}9.8 \pm 0.9 \\
7.8 \pm 1.1\end{array}$ & $\begin{array}{l}7.6 \pm 1.0 \\
6.7 \pm 1.1\end{array}$ & $\begin{array}{l}5.0 \pm 0.8 \\
4.7 \pm 0.7\end{array}$ \\
\hline Sagittal sinus $\mathrm{O}_{2}$ content $(\mathrm{mL} / \mathrm{dL})$ & $\begin{array}{l}\text { I } \\
\text { II }\end{array}$ & $\begin{array}{l}8.5 \pm 0.8 \\
6.1 \pm 0.8\end{array}$ & $\begin{array}{l}1.8 \pm 0.3 \\
1.8 \pm 0.4\end{array}$ & $\begin{array}{l}1.5 \pm 0.3 \\
1.3 \pm 0.3\end{array}$ & $\begin{array}{l}1.2 \pm 0.3 \\
1.2 \pm 0.3\end{array}$ & $\begin{array}{l}1.1 \pm 0.4 \\
1.0 \pm 0.4\end{array}$ & $\begin{array}{l}0.6 \pm 0.2 \\
0.7 \pm 0.2\end{array}$ \\
\hline Cerebral $\mathrm{O}_{2}$ uptake $\left(\mathrm{mL} \mathrm{O}_{2} / \mathrm{min} / 100 \mathrm{~g}\right)$ & $\begin{array}{l}\text { I } \\
\text { II }\end{array}$ & $\begin{array}{l}2.5 \pm 0.3 \\
2.6 \pm 0.3\end{array}$ & $\begin{array}{l}1.4 \pm 0.3 \\
0.8 \pm 0.1 \uparrow\end{array}$ & $\begin{array}{l}1.1 \pm 0.2 \\
0.7 \pm 0.2\end{array}$ & $\begin{array}{l}0.7 \pm 0.1 \\
0.3 \pm 0.1\end{array}$ & $\begin{array}{l}0.3 \pm 0.1 \\
0.2 \pm 0.1\end{array}$ & $\begin{array}{l}0.1 \pm 0.1 \\
0.1 \pm 0.1\end{array}$ \\
\hline $\mathrm{O}_{2}$ extraction & $\begin{array}{l}\text { I } \\
\text { II }\end{array}$ & $\begin{array}{l}0.39 \pm 0.04 \\
0.45 \pm 0.05\end{array}$ & $\begin{array}{l}0.86 \pm 0.03 \\
0.83 \pm 0.03\end{array}$ & $\begin{array}{l}0.86 \pm 0.03 \\
0.85 \pm 0.02\end{array}$ & $\begin{array}{l}0.87 \pm 0.02 \\
0.81 \pm 0.03\end{array}$ & $\begin{array}{l}0.83 \pm 0.04 \\
0.87 \pm 0.02\end{array}$ & $\begin{array}{l}0.84 \pm 0.04 \\
0.85 \pm 0.02\end{array}$ \\
\hline Mean intracranial pressure $(\mathrm{mm} \mathrm{Hg})$ & II & $\begin{array}{l}5 \pm 1 \\
5 \pm 1\end{array}$ & $\begin{array}{l}29 \pm 4 \\
27 \pm 4\end{array}$ & $\begin{array}{l}28 \pm 4 \\
30 \pm 3\end{array}$ & $\begin{array}{l}25 \pm 3 \\
26 \pm 4\end{array}$ & $\begin{array}{l}24 \pm 3 \\
27 \pm 5\end{array}$ & $\begin{array}{l}24 \pm 3 \\
26 \pm 5\end{array}$ \\
\hline Mean sagittal sinus pressure $(\mathrm{mm} \mathrm{Hg})$ & $\begin{array}{l}\text { I } \\
\text { II }\end{array}$ & $\begin{array}{l}5 \pm 1 \\
6 \pm 1\end{array}$ & $\begin{array}{l}32 \pm 5 \\
28 \pm 3\end{array}$ & $\begin{array}{l}32 \pm 5 \\
33 \pm 3 \\
\end{array}$ & $\begin{array}{l}29 \pm 2 \\
32 \pm 3 \\
\end{array}$ & $\begin{array}{l}30 \pm 2 \\
33 \pm 4 \\
\end{array}$ & $\begin{array}{l}30 \pm 2 \\
32 \pm 5\end{array}$ \\
\hline
\end{tabular}

* Group I, conventional CPR; group II, SCV-CPR.

$+p<0.05$ versus group 1 value.

sure averaged over the CPR cycle were equivalent (Table 2). These pressures remained unchanged during prolonged CPR and were not different between groups.

\section{DISCUSSION}

The major findings of this study are 2-fold. First, in contrast with studies in large adult dogs, SCV-CPR does not increase intrathoracic vascular pressures, and does not enhance either cerebral perfusion and oxygen uptake or myocardial perfusion when compared with conventional CPR. Second, SCV-CPR does not sustain cerebral and myocardial blood flow better than conventional CPR when CPR is extended for prolonged periods.

Several investigators have demonstrated in large dogs $(>20 \mathrm{~kg})$ that SCV-CPR, with peak airway pressures of $80-100 \mathrm{~mm} \mathrm{Hg}$, substantially increased intrathoracic and intravascular pressures when compared with conventional CPR $(3,4,6)$. In the study by Luce et al. (6), SCV-CPR with ventilation at $80 \mathrm{~mm} \mathrm{Hg}$ airway pressure increased intrathoracic pressure from 24 to 70 $\mathrm{mm} \mathrm{Hg}$ when compared with conventional CPR. Koehler et al. (4) demonstrated that changing from conventional CPR to SCVCPR with ventilation at $80-90 \mathrm{~mm} \mathrm{Hg}$ airway pressure increased mean carotid arterial pressure from 27 to $64 \mathrm{~mm} \mathrm{Hg}$. However, studies with smaller dogs (7-12 kg) failed to demonstrate superiority of SCV-CPR $(17,18)$. In these latter studies there were no differences in the peak intrathoracic vascular pressures that were achieved by the two CPR modalities performed with conventional chest pads. It is notable in both these studies that intrathoracic vascular pressures generated in each CPR group exceeded the 55-70 mm Hg peak airway pressure used for the delivery of SCV-CPR.

Our investigation in piglets, the smallest animal that has been used for SCV-CPR research, also demonstrated that SCV-CPR did not increase intrathoracic pressure, as reflected by peak right atrial pressure, when compared with conventional CPR. Conventional CPR generated an intrathoracic pressure of $85 \mathrm{~mm} \mathrm{Hg}$, a value that exceeded the peak airway pressure of $60 \mathrm{~mm} \mathrm{Hg}$ achieved during SCV-CPR. Frequent tension pneumothoraces with ventilation at peak airway pressures of more than $60 \mathrm{~mm}$ $\mathrm{Hg}$ precluded the use of high airway pressures in piglets. The use of SCV-CPR with peak airway pressures that are less than the intrathoracic pressure that can be generated by conventional CPR would not be expected to produce a further increment in intrathoracic pressure. Therefore, the lack of superiority of SCV. $\mathrm{CPR}$ in infant piglets, as in small dogs, is probably due to the relatively high intrathoracic pressure generated by conventional CPR in these models.

We believe that the reason for the high intrathoracic pressure achieved with conventional CPR in piglets is related to the shape and deformability of the chest of infant piglets. Because the cross sectional shape of the thorax in piglets and small dogs is more circular than that of large dogs, cyclic sternal displacement of similar percent of the anteroposterior diameter will produce a greater percent decrease in cross-sectional area in piglets and small dogs (12). Moreover, in piglets the chest does not fully recoil in between compressions and the chest shape becomes elliptical. Consequently, the $20 \%$ cyclic displacement on the minor axis of the ellipse produces considerably greater cyciic decreases in cross-sectional area and hence greater increases in intrathoracic pressure (12). Because human infants have deformable chests with an elliptical rather than circular cross-section. we anticipate that sternal displacement on the minor axis of the ellipse would produce high intrathoracic pressure when CPR is performed in the conventional manner. Thus, SCV-CPR is ut likely to provide a further advantage in human infants.
In large do६ tional or $\mathrm{SCl}$ in noncerebr: sure but not myocardial bl epinephrine is was extremel: kept aortic pr provided a co the chest relar the significant

CPR. During mained extrer in aortic pres: due to impaire This decline is the stable perf flow seen in do of CPR (7).

Although Si not augment CPR may be b apparent decli either by assis through the I develops with flow by distort into the chest deformity and creased such tl the relaxation unchanged rigt in both groups mining atrial $f$ of pleural pres! neous ventilati however, splin1 progressive che in an isolated, augmented cari low, but not । swings appeare compression of appear to provi it is more likel proximal to the in abdominal $\mathrm{v}$ accompanying each chest com lance, and this than mature do We used a cc CPR as recomn lines for infant 1 SCV-CPR. We higher rates de' perinflation. M indicated that $\mathrm{F}$ sitive to comps conventional $\mathrm{Cl}$ compression rat factor in affectir not designed to CPR and the re pump mechanis tardiac compre: generation in ea In this study, igher with $\mathrm{SC}^{\prime}$ ogs, intracrani ncreased during 
In large dogs epinephrine administration during either convennal or SCV-CPR causes selective peripheral vasoconstriction $50 \mathrm{~min}$

$88 \pm 16$

$163 \pm 46$

$52 \pm 9$

$89 \pm 10+$

$6.73 \pm 0.05$

$6.62 \pm 0.04$

$4.5 \pm 0.4$

$4.1 \pm 0.6$

$76 \pm 9$

$78 \pm 1$

$5.0 \pm 0.8$

$4.7 \pm 0.7$

$0.6 \pm 0.2$

$0.7 \pm 0.2$

$0.1 \pm 0.1$

$0.1 \pm 0.1$

$0.84 \pm 0.04$

$0.85 \pm 0.02$

$24 \pm 3$

$26 \pm 5$

$30 \pm 2$

$32 \pm 5$

:d that SCV-CPR sted by peak right ral CPR. Conven? of $85 \mathrm{~mm} \mathrm{Hg}$, a e of $60 \mathrm{~mm} \mathrm{Hg}$ pneumothoraces nore than $60 \mathrm{~mm}$ in piglets. The use are less than the by conventional ther increment in uperiority of SCV. obably due to the $\mathrm{d}$ by conventional

athoracic pressure elated to the shape Because the cross mall dogs is more al displacement of ter will produce a rea in piglets and est does not fully st shape becomes placement on the ably greater cyclic reater increases in fants have deform:ular cross-section, $\geqslant$ minor axis of the sure when CPR is , SCV-CPR is unn infants. noncerebral and noncoronary beds, which raises aortic presre but not right atrial pressure (7). Thus, the gradient for gyocardial blood flow is enhanced. In our study with continuous inephrine infusion, blood flow to noncerebral peripheral tissue pas extremely low (Table 1). This peripheral vasoconstriction vept aortic pressure elevated in between chest compressions and rovided a consistent gradient for myocardial blood flow during the chest relaxation phase of the CPR cycle. This accounted for he significant myocardial blood flow in both groups during early CPR. During prolonged CPR, peripheral tissue blood flow remained extremely low. This suggests that the progressive decline aortic pressure and consequent decline in MBF and $\mathrm{CBF}$ is due to impaired venous return and not to peripheral vasodilation. This decline in aortic pressure in piglets is in marked contrast to the stable perfusion pressure and myocardial and cerebral blood low seen in dogs with epinephrine infusion over a 50 -min period CPR (7).

Although SCV-CPR at an airway pressure of $60 \mathrm{~mm} \mathrm{Hg}$ did not augment intrathoracic pressure, we postulated that SCVCPR may be beneficial during prolonged CPR by preventing this apparent decline in venous return and pulmonary blood flow cther by assisting chest recoil or by cyclically propelling blood through the lungs $(13,14)$. Progressive chest deformity that develops with prolonged CPR could obstruct pulmonary blood low by distorting intrathoracic vessels or impede venous return into the chest. It is possible that with progressive chest wall deformity and distortion, chest wall compliance might be increased such that intrapleural pressure becomes positive during the relaxation phase of CPR. If this occurs in the presence of an unchanged right atrial pressure, as was demonstrated during CPR in both groups in this study, then the transmural pressure determining atrial filling might be compromised. No measurements of pleural pressure were, however, made in this study. Simultaneous ventilation at high airway pressure in this study did not, however, splint the chest wall or assist in chest recoil to prevent progressive chest deformity. Hausknecht et al. (13) demonstrated in an isolated, heart-lung model of CPR that lung inflation augmented cardiac output when swings in pleural pressure were low, but not when they were high. Because pleural pressure swings appeared to remain high when $\mathrm{CPR}$ was prolonged, cyclic compression of pulmonary capillaries by lung inflation does not appear to provide any significant benefit in this situation. Thus, it is more likely that there is some impediment to blood flow proximal to the pulmonary bed or that there is pooling of blood in abdominal veins. Repetitive cyclic stretch of splanchnic veins scompanying retrograde inferior vena caval blood flow during ach chest compression may gradually increase venous capaciance, and this effect may be more prominent in immature pigs han mature dogs.

We used a compression rate of $100 /$ min during conventional CPR as recommended by the American Heart Association guideines for infant CPR (19), whereas a rate of $60 / \mathrm{min}$ was used for SV-CPR. We found that animals subjected to SCV-CPR at igher rates developed pneumothoraces secondary to lung hyerinflation. Moreover, preliminary studies in our laboratory idicated that perfusion pressure gradients are relatively insenitive to compression rate between 60 and $100 / \mathrm{min}$ during onventional CPR in infant piglets (20). Thus, the difference in ompression rates between groups is probably not a significant ctor in affecting organ blood flow in this study. This study was ot designed to elucidate the mechanism of blood flow during PR and the results do not necessarily imply that the thoracic ump mechanism is responsible for antegrade blood flow. Direct ardiac compression remains a possible mechanism for flow theration in each of the CPR groups in this animal model.

In this study, cerebral blood flow and $\mathrm{O}_{2}$ uptake were not gher with SCV-CPR than with conventional CPR. In adult gos, intracranial pressure increases when airway pressure is creased during SCV-CPR, but the increase in aortic and carotid pressure is even greater (21), thereby enhancing cerebral blood flow (4). In contrast in this study, there was no difference between the CPR groups in either the upstream (aortic) or downstream pressures (either intracranial or sagittal sinus pressures) because intrathoracic pressure was equivalent. Under certain circumstances, aortic pressure may exceed carotid pressure because of collapse of the intrathoracic arteries at the thoracic inlet and cerebral perfusion pressure may be overestimated (7). However, CBF was similar in each group, suggesting that any overestimation of cerebral perfusion pressure by using aortic pressure was similar between groups.

The level of CBF achieved during conventional CPR in this study is lower than those from a previous study on piglets from this laboratory (11). However, in that study an adult chest pad was used, whereas in this study a pediatric chest pad was used. With the pediatric chest pad, less compressive force was required to produce $20 \%$ sternal displacement directly under the pad because the force was applied over a smaller surface area. However, this pad produces less displacement over the more rostral segment of the sternum because the hemisphere on the pediatric pad is not in contact with the rostral segment. Thus, the increase in intrathoracic pressure is somewhat less than that with the larger, flat adult pad. This may account for the slightly lower aortic pressures generated in this investigation than those achieved in the previous study.

Despite altering the concentration of inspired $\mathrm{CO}_{2}$ to maintain the arterial $\mathrm{PCO}_{2}$ uniform in both groups, $\mathrm{PCO}_{2}$ was higher in the SCV-CPR group. In both groups, $\mathrm{PCO}_{2}$ increased with prolonged CPR. The effect of hypercarbia and acidosis under circumstances of low CBF with prolonged CPR in this study is unclear. However, we suspect that differences between groups due to direct effects of $\mathrm{CO}_{2}$ on cerebral vessels is small because the vessels are probably maximally vasodilated under circumstances of maximal fractional $\mathrm{O}_{2}$ extraction (22). The increase in blood flow solely to the medulla at $10 \mathrm{~min}$ of SCV-CPR may, however, be accounted for by the increase in $\mathrm{PCO}_{2}$ in that group. Hansen $e t$ al. (23) demonstrated in newborn piglets that there are regional differences in the response of cerebral blood flow to hypercarbia. In that study there was a greater increase in blood flow to the brain stem, cerebellum, and thalamus than to the cerebrum.

The $\mathrm{Hb}$ concentration in both groups of animals decreased by approximately $40 \%$ during $50 \mathrm{~min}$ of CPR. This was probably caused by hemodilution, because each animal received $220 \mathrm{~mL}$ of crystalloid infusion during resuscitation. There was no necropsy evidence of extravascular blood loss such as liver rupture that, in addition, might have contributed to the decline in hematocrit.

In summary, we have shown that SCV-CPR does not enhance cerebral and myocardial perfusion during early CPR in this infant animal model or CPR presumably because intrathoracic pressure generation is already high with conventional CPR. In addition, SCV-CPR does not prevent the progressive deformity of the infant animal chest when CPR is prolonged and does not mitigate the subsequent deterioration of $\mathrm{CBF}$ and $\mathrm{MBF}$.

Acknowledgments. The authors thank Susan Hacker and Nikki Womer for their fine secretarial assistance in preparing this manuscript.

\section{REFERENCES}

Rudikoff MT, Maughan WL, Effron M, Freund P, Weisfeldt ML 1980 Mechanisms of blood flow during cardiopulmonary resuscitation. Circulation $61: 345-362$

2. Weisfeldt ML, Chandra N 1981 Physiology of cardiopulmonary resuscitation. Annu Rev Med 32:435-442

3. Chandra N, Weisfeldt ML, Tsitlik J, Vaghaiwalla F, Snyder LD, Hoffecker M, Rudikoff MT 1981 Augmentation of carotid flow during cardiopulmonary resuscitation by ventilation at high airway pressure simultaneous with chest compression. Am J Cardiol 48:1053-1063

4. Koehler RC, Chandra N, Guerci AL, Tsitlik J, Traystman RJ, Rogers MC, Weisfeldt ML 1983 Augmentation of cerebral perfusion by simultaneous chest compression and lung inflation with abdominal binding after cardiac arrest in dogs. Circulation 67:266-275 
5. Halperin HR, Tsitlik JE, Guerci AD, Mellits ED, Levin HR, Shi AY, Chandra N, Weisfeldt ML 1986 Determinants of blood flow to vital organs during cardiopulmonary resuscitation in dogs. Circulation 73:539-550

6. Luce JM, Ross BK, O'Quin RJ, Culver BH, Sivarajan M, Amory DW, Niskanen RA, Alferness CA, Kirk WL, Pierson LB, Butler J 1983 Regional blood flow during cardiopulmonary resuscitation in dogs using simultaneous and nonsimultancous compression and ventilation. Circulation 67:258-264

7. Michael JR, Guerci AD, Koehler RC, Shi AY, Tsitlik J, Chandra N, Niedermeyer E, Rogers MC, Traystman RJ, Weisfeldt ML 1984 Mechanisms by which epinephrine augments cerebral and myocardial perfusion during cardiopulmonary resuscitation in dogs. Circulation 69:822-835

8. Chandra N, Rudikoff M, Weisfeldt ML 1980 Simultaneous chest compression and ventilation at high airway pressure during cardiopulmonary resuscitation. Lancet 1:175-178

9. Zaritsky A 1986 Advanced pediatric life support: state of the art. Circulation 74(suppl IV):124-128

10. Fleisher G, Delgado-Paredes C, Heyman S 1987 Slow versus rapid closed-chest cardiac compression during cardiopulmonary resuscitation in puppies. Crit Care Med 15:939-943

11. Schleien CL, Dean JM, Koehler RC, Michael JR, Chantarojanasiri T, Traystman R, Rogers MC 1986 Effect of epinephrine on cerebral and myocardial perfusion in an infant animal preparation of cardiopulmonary resuscitation. Circulation 73:809-817

12. Dean JM, Koehler RC, Schleien CL, Michael JR, Chantarojanasiri T, Rogers MC, Traystman RJ 1987 Age-related changes in chest geometry during cardiopulmonary resuscitation. J Appl Physiol 62:2212-2219

13. Hausknecht MJ, Wise RA, Brower RG, Hassapoyannes C, Weisfeldt ML, Suzuki J, Permutt S 1986 Effects of lung inflation on blood flow during cardiopulmonary resuscitation in the canine isolated heart-lung preparation.

\section{Circulation 59:676-683}

14. Passerini L, Wise RA, Roussos C, Magder S 1988 Maintenance of circulation without chest compression during CPR. J Crit Care 3:96-102

15. Nichols DG, Ketrick RG, Swedlow DB, Scott L, Passman R, Ludwig S 1986 Factors influencing the outcome of cardiopulmonary resuscitation in 1986 dren. Pediatr Emerg Care 2:1-5

16. Heymann MA, Payne BD, Hoffman JR, Rudolph AM 1977 Blood flo measurements with radionuclide-labeled particles. Prog Cardiovasc Dis $20: 5$

17. Babbs CF, Tacker WA, Paris RC, Murphy FJ, Davis RW 1982 CPR simultaneous compression and ventilation at high airway pressure in four animal models. Crit Care Med 10:501-504

18. Sanders AB, Ewy GA, Alferness CA, Taft T, Zimmerman M 1982 Failure of one method of simultaneous chest compression, ventilation, and abdominal binding during CPR. Crit Care Med 10:509-513

19. Standards and guidelines for cardiopulmonary resuscitation and emergency cardiac care. 1986 JAMA 255:2905-2932

20. Koehler RC, Dean JM, Schleien CL, Berkowitz ID, Michael JR, Atchison D Rogers MC, Traystman RJ 1987 Effect of compression rate and duty cycle on cerebral perfusion pressure during cardiopulmonary resuscitation in swine. Anesthesiology 67:A152(abstr)

21. Guerci AD, Shi AY, Levin H, Tsitlik J, Weisfeldt ML, Chandra N 1985 Transmission of intrathoracic pressure to the intracranial space cardiopulmonary resuscitation in dogs. Circ Res 56:20-30

22. McPherson RW, Eimerl D, Traystman RJ 1987 Interaction of hypoxia and hypercapnia on cerebral hemodynamics and brain electrical activity in dogs. Am J Physiol 253:H890-H897

23. Hansen NB, Brubakk AM, Bratlid D, Oh W, Stonestreet BS 1984 The effects of variations in $\mathrm{PaCO}_{2}$ on brain blood flow and cardiac output in the newborn piglet. Pediatr Res 18:1132-1136

\section{Annual Meeting of the Society for Adolescent Medicine}

The Society for Adolescent Medicine will hold its annual meeting March 22-25, 1990, at the Hilton Hotel and Towers, Atlanta, GA. The meeting will address new material on a broad range of issues important to adolescent physical and emotional health: AIDS, teenage sexuality and pregnancy, eating disorders, depression, and risk-taking behaviors, including suicide and violence. Meeting presentations include all-day workshops, 3-h clinically oriented workshops, research networking breakfasts and luncheon seminars, scientific research paper presentations and poster sessions, as well as the prestigious Gallagher Lecture Series. Special symposia will be offered in conjunction with the Centers for Disease Control and the Society for Research on Adolescence. CME/CEU credit available. For information contact the Society for Adolescent Medicine, Suite 101, 10727 White Oak Avenue, Granada Hills, CA 91344, (818) 368-5996.

\section{Abstract Deadline}

The American Pediatric Society and The Society for Pediatric Research announce the abstract deadline for the 1990 Annual Meeting (May 7-11, 1990, Anaheim Hilton \& Convention Center, Anaheim, CA) has been set as January 4, 1990.

For further information contact: 2650 Yale Blvd., S.E., Suite 104, Albuquerque, NM 87106 (505) 764-9099.

\section{Hyperlipidemia in Childhood and the Development of Atherosclerosis}

A conference on Hyperlipidemia in Childhood and the Development of Atherosclerosis will be held May 2-4, 1990, at the Hyatt Regency, Bethesda, MD. This conference will examine the role of hyperlipidemia and dyslipidemia in childhood in relation to the development of atherosclerosis. The program will focus initially on morphologic development of the atherosclerotic plaque, pathologic findings in pediatric autopsy series, biochemical correlates, and cellular models of atherosclerosis in the young. Distribution of plasma cholesterol and lipoprotein levels in children will be reviewed, including genetic, dietary, developmental, lifestyle, and pharmacologic influences on serum levels. Tracking of lipid levels over time will be reviewed, as well as international comparisons of lipids in pediatric populations. Cholesterol screening of children will be presented both from high-risk and population-based viewpoints. Pediatric office-based, school-based, and communitywide cholesterol screening activities and interventions will be described. Dietary and pharmacologic therapy of lipid disorders in children will be presented. Abstract deadline is December 11,1989. The abstract, including title, author(s), and affiliation must be typed single space within a $5 \times 4-3 / 8$ inch rectangle, and sent to Dr. Christine L. Williams, Preventive Cardiology Center, New York Medical College, Valhalla, NY 10595. For further information, contact Conference Department, The New York Academy of Sciences, 2 East 63rd Street, New York, NY 10021, (212) 838-0230. 